\title{
Integration of BIM, Web Maps and IoT for Supporting Comfort Analysis
}

\author{
M. Gunduz ${ }^{\mathrm{a}}$, U. Isikdag ${ }^{\mathrm{b}}$ M. Basaraner ${ }^{\mathrm{a}}$ \\ ${ }^{a}$ Yildiz Technical University, Dept. of. Geomatic Engineering, Istanbul Turkey - memogedo@ gmail.com; mbasaran@yildiz.edu.tr \\ ${ }^{\mathrm{b}}$ Mimar Sinan Fine Arts University, Dept. of Informatics, Istanbul Turkey - uisikdag@ gmail.com
}

KEY WORDS: Facility Management, Web Maps, BIM, IoT, Sensor, Google Maps

\begin{abstract}
:
The use of the Internet is expanding and the technological capabilities of electronic devices are evolving. Today, Internet of Things (IoT) solutions can be developed that were never even imaginable before. In this paper, a case study is presented on the joint use of Building Information Model (BIM), Geographical Information Systems (GIS) and Internet of Things (IoT) technologies. It is a part of an ongoing study that intends to overcome some problems about the management of complex facilities. In the study, a BIM has been converted and displayed in 2D on Google Maps, and information on various sensors have been represented on the web with geographic coordinates in real-time.
\end{abstract}

\section{INTRODUCTION}

Collaborative use of BIM, GIS and IoT technologies allow developing new kinds of applications in many fields, including Facility Management (FM). While GIS is primarily a technology used in urban planning, municipal management and asset management, it can also be a very convenient tool for FM (IFMA, 2012). Although it is still not used as the primary tool for Facility Management, the GIS appears as an accessible platform for many disciplines. Referring to the importance of data collection and analysis in facilities management, Barret and Finch (2014) stated that BIM will be attractive to the management of a plant during the design, construction and operation phase.

Users can make useful suggestions for existing or future buildings by analyzing the data collected from the building, but users are not accepting new technologies immediately. IoT includes the use of sensors and near field communication equipment, such as RFIDs or NFC, together with embedded computing devices. Devices can range from mobile phones to RFID readers, GPS devices to tablets, automotive control systems, air stations. In the IoT environment, you can make a connection with a door fire alarm, or you can communicate with the house lights in your chair or communicate with a car park. (Isikdag, 2015). In other words, we can use IoT technologies in Facility Management to collect the required data.

The comfort of the residents is an important subject for facility management. Nowadays, with the technological progress in industry a comfort analysis is possible. Our proposed research aims to gather information from sensors at different locations in a facility to form a basis for a comfort analysis.

Roper and Borello (2014) argue that, the quality of the indoor environment affects the workplace performance on an individual level. In this context, it can be listed six basic factors that affect comfort in the interior:
- Temperature and relative humidity

- $\quad$ Sound management

- Lighting

- Aesthetics

- Ergonomics

- Social interaction in the workplace

Based on these parameters, it is possible to determine which type of information needs to be acquired and what type of sensors should be used to maintain facility comfort. In order to support a comfort analysis, study the data acquired from the sensors can be displayed on the map and can be monitored instantaneously and necessary interventions can be carried out or various analyzes can be performed. As a result of these analyzes, the solutions to comfort related problems can be determined.

\section{BACKGROUND}

The literature in the field covers various efforts for integrating BIM-GIS and IoT. For instance, Deng, Cheng, \& Anumba (2016) integrated building information modelling (BIM) and 3D GIS in order to combine traffic noise evaluation in both outdoor environments and indoor environments in a single platform. Liu et al. (2017) explained that the integration of Building Information Modeling (BIM) and Geographic Information System (GIS) has been identified as a promising but challenging topic to transform information towards the generation of knowledge and intelligence. Achievement of integrating these two concepts and enabling technologies will have a significant impact on solving problems in the civil, building and infrastructure sectors. However, since GIS and BIM were originally developed for different purposes, numerous challenges are being encountered for the integration.

To better understand these two different domains, their work reviews the development and dissimilarities of GIS and BIM, the existing integration methods, and investigates their 
potential in various applications. This study shows that the integration methods are developed for various reasons and aim to solve different problems. Bansal and Pal (2009) proposed a method for direct sunlight visualization to calculate the amount of sunlight received on different faces of a building by integrating BIM with GIS. Energy required on an urban scale level was also forecasted in the integrated 3D city system (Strzalka et al., 2011), and the impacts of different levels of building details on the energy demand were also illustrated in this study. Potential also exists in identifying the relationship among environmental impact, urban density and solar gains, thereby estimating the necessary building energy consumption (Strømann-Andersen and Sattrup, 2011).

GIS and BIM can help with investigating the dynamic relationship between weather conditions, urban geometry, and individual building's properties. Such a system will improve urban planning and building design in terms of energy optimization. Niu et al. (2015) improved it by developing a web-based system to visualize and inspect energy consumption at both building and urban level. In addition, Castro- Lacouture, et al. (2014) presented a conceptual GISBIM framework about algae power generation system to improve the energy consumption at the level of urban neighborhood. Kang \& Hong (2015), Kang et al. (2016) proposed a BG-ETL architecture for the effective integration of data from heterogeneous systems of BIM, GIS, and FM. From the practical viewpoint of data integration, data were divided according to their geometry and property information, allowing the problem of GIS and BIM-based information interoperability to be addressed.

To visualize numerous objects represented over the GIS, a simplified surface model was converted using IFC geometrical information, whereas property information was extracted and transformed to obtain the required information from a use-case perspective by utilizing BG-ETL. Applying BG-ETL, authors have designed an effective architecture for the support of information interoperability between heterogeneous BIM, GIS, and FM systems, and developed a prototype that implemented FM use cases. Thus, the authors verified the effective integration of the required data from the project stakeholder's perspective. Laat and Berlo (2011) present a research where a mix of strong parts from both worlds is integrated in a single project. The paper describes the development of a CityGML extension called GeoBIM to get semantic IFC data into a GIS context. The conversion of IFC to CityGML (including the GeoBIM extension) is implemented in the open source Building Information Model server.

Kassem M. et al. (2014) mentioned that a BIM visualization provides accurate geometrical data that has never been possible before and can support the analysis of building proposals and the simulation and benchmark of performance (Atkin and Brooks, 2009). Wang et al. (2016) proposed a framework, where a profile is created for each existing vacant facility by combining BIM and GIS attributes. As a result, these profiles can be matched to the desired BIM model, which the aspiring users have provided, based on a weighted distance calculation. The framework presents the most suitable vacant facilities to the users to promote facility reuse.
El-Gamily and Al-Rasheed (2015) presented a study which aims at building a comprehensive geodatabase for different elements of infrastructure facilities and services on the building bases for a selected number of schools and developing a GIS based iFaME interactive application to manage different facilities at the school level in Kuwait. The research of Petrenko et al. (2014) outlines the potential for employing indoor wireless network positioning and sensorbased systems to improve the collection of tracking data indoors. By applying various methods of GIScience authors developed a methodology that can be applicable for diverse human indoor mobility analysis. Barret and Finch (2014) mentioned that the UK government has embraced the concept of BIM (as detailed in the Building Information Modelling (BIM) Working Party Strategy document), requiring threedimensional BIM (including all project and asset information, documentation and data) for all public assets by 2016. At the heart of this strategy is a building information model known as COBie, the Construction Operations Building Information Exchange. One of the appealing features of COBie is that it is possible to represent the COBie model using a simple spreadsheet (e.g. Excel, Lotus Notes). Roper and Borello (2014) indicated that whether it is precise control of temperature and humidity for worker comfort or process control or monitoring of critical components, such as lighting, fuel tanks, and power systems, advanced technologies allow a more accurate and controllable building. Additional integrations may involve providing secure authorized access control for time and attendance or for security access, alarm monitoring, and fire and smoke detection.

Deng et al. (2016) presented a study where Industry Foundation Classes (IFC) and City Geography Markup Language (CityGML) were chosen as the key schemas due to their wide applications in the BIM domain and the GIS domain, respectively. The authors used an instance-based method to generate the mapping rules between IFC and CityGML based on the inspection of entities representing the same component in the same model. It ensures accurate mapping between the two schemas. The transformation of coordinate systems and geometry are two major issues addressed in the instance based method. Considering the difference in schema structure and information richness between the two schemas, a reference ontology called Semantic City Model was developed and an instance-based method was adopted.

Begun and Saha (2017) presented a case study which pertains to meet the objectives like collection of information on various facilities (viz., Banks and ATM, Photocopy and Printout shops, Food Joints, Health Care and Medical shops, Hostels, etc.) in the Delhi University North Campus and collating that information to develop the facility management system in a GIS framework. GIS-based network analysis to find out basic closest facilities, optimized route identification, service area identification, origin-distance matrix etc. To improve evacuation efficiency, an evacuation system was proposed by Liu and Zhu (2014) based on GIS and Technology of IoT by analyzing the influence of smoke on evacuation. Information about the building can be obtained using GIS and IoT technology. Using Matlab based on analytic hierarchy process for three evaluations, Evacuation path selection, one of the most critical problems in the system, could be solved. The article provides a new approach, a new idea, for achieving 
building fire evacuation. It also promotes the intellectualization of fire protection.

According to CABA (2002) the major benefits of intelligent buildings are as follows:

- Increased individual environmental control leading to higher value building, leasing and rental potential.

- Managed energy consumption through zone control on a time-of-day schedule.

- Upgrading and modifications to control systems from standardized systems wiring.

- Control of building systems after hours via PC, PDA or telephone.

- Tracking of occupant after-hours system.

- Tracking of service/replacement history of individual zone use.

- Control of changes to telephone, security, LAN, wireless devices, parking

According to Brian and Brooks (2009) sensors will be deeply embedded within building structures, supplying data when scanned for shear, strain, pressure and other forces that can affect them, using wireless networks to return the scanned results to a data center, thereby saving the expense of sending out safety inspectors and engineers to monitor the structures. A problem common to both these developments is battery life the devices switch on only for brief periods to update measurements and use very short-range communications by passing data from one device to the next across the network.

For many applications in the built environment, it is impractical to change batteries and some form of solar or other energy support is needed. The future of these devices, once the problems of miniaturization and cost have been solved, is a fundamental solution to one of the most pressing economic problems of today runaway energy costs. Once distributed around a building, the sensors would form a network relaying data about each room's temperature, light, humidity, occupancy, etc. to a central computer that would regulate energy use in the building, optimizing the energy delivery to each room and using passive heating and ventilation control methods wherever possible. The emerging smart-energy technology could save significantly on electricity costs, as buildings currently drain away more than a third of the total energy supply of some countries. According to Lee et al. (2016) managers can use information technology to support operation and maintenance of buildings. Moreover, a web-based platform allows users to manage facilities intuitively without investing on professionals or specialized software.

\section{METHODOLOGY AND EXPERIMENTAL DESIGN}

This study aims at presenting and testing a sample software architecture for the integration of BIM, GIS and IoT for supporting Comfort Analysis.

In order to collect real-time data from the building, Arduino (Figure 1) hardware was used as a prototyping tool, which is. an open source electronic platform (Arduino, 2017). With Arduino, all the input data can be converted into an output. These entries can even be a sensor, a button, or a Twitter message. As output, the output itself can be data or data that activates a motor or opens an LED. All these transactions can be done online. To do this, Arduino offers programming language (Wiring-based) and Arduino software (IDE)

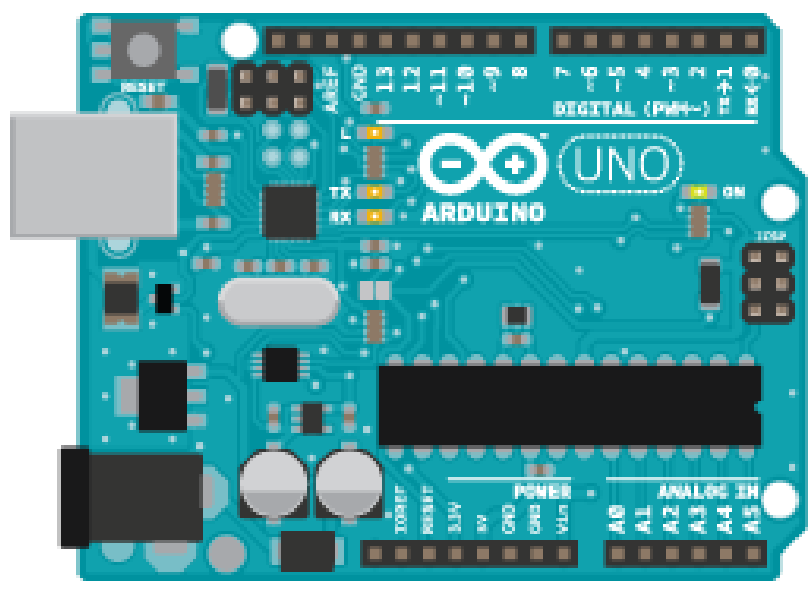

Figure 1. Arduino (https://www.arduino.cc/)

Using the Arduino tool, the authors have collected data from different sensors such as temperature, humidity, and light level sensors. These sensors can be installed in various places of the facility, and in different facilities. Once the Arduino is connected to the Internet, one can instantly get the data from the sensors that are connected to the Arduino hardware. The authors have developed code to integrate the geo-coordinates for each sensor with the information acquired from the sensors and provided an information output in GeoJSON format. The output also contains semantic information such as the definition of the sensor, current value of the sensor, the room that the sensor is located.

In order to test the integration approach a two-storey building (Figure 4) was chosen as the case study example, but only one floor was used in the implementation. The building's BIM was in IFC format at the first stage and was converted to twodimensional shp format using SAFE FME software.

As described on the official site FME (2017) the FME (originally, the "Feature Manipulation Engine") is working with the ETL (Extraction, Conversion, and Installation) principle. So, the software can be defined as a tool that extracts data from a source, transforms it to meet the needs of users, and then uploads it to a target or database.

Figure 2 presents the workbench screenshot where FME is used to transform the Slabs of an IFC model to 2D ESRI .shp file. The transformation file can be downloaded from (http://labs.isikdag.com/IFCSlabsTo2DUmit.fmw)

In the next stage the Google Maps API is used for map visualization of information that is acquired from the sensors that are connected to the Arduino. The integration approach was towards visualizing all information within Google Maps by utilizing the GeoJSON format. Since Google Maps supports the GeoJSON format, the case study building model that was converted earlier from IFC to .shp format, then was converted to GeoJSON format with the help of QGIS software. The integration architecture is shown in Figure 3. 
Following the conversion of building information to GeoJSON, the model of the facility has been visualized on the Google Maps. In summary, the data acquired from the sensors and presented in form of GeoJSON, and the representation of the floor plan of the facility presented in form of GeoJSON were visualized using the Google Maps Environment. The proposed architecture and the implementation enabled the visualization of real-time information regarding the sound, light levels, temperature of rooms at a web based online mapping environment.
Figure 4 and Figure 5 provides a depiction regarding the visualization of Integrated Information. In Figure 5 the red marks shows the geolocation of the sensors, the floor plan of the building that is acquired from the IFC and converted to the GeoJSON is presented in green color. Semantic information such as the definition of the sensor, current value of the sensor, the room that the sensor is located, is also provided together with the visualization.

The information provided as a result of BIM-IoT integration and visualization of information using Web Mapping technology will be beneficial for performing comfort analysis.

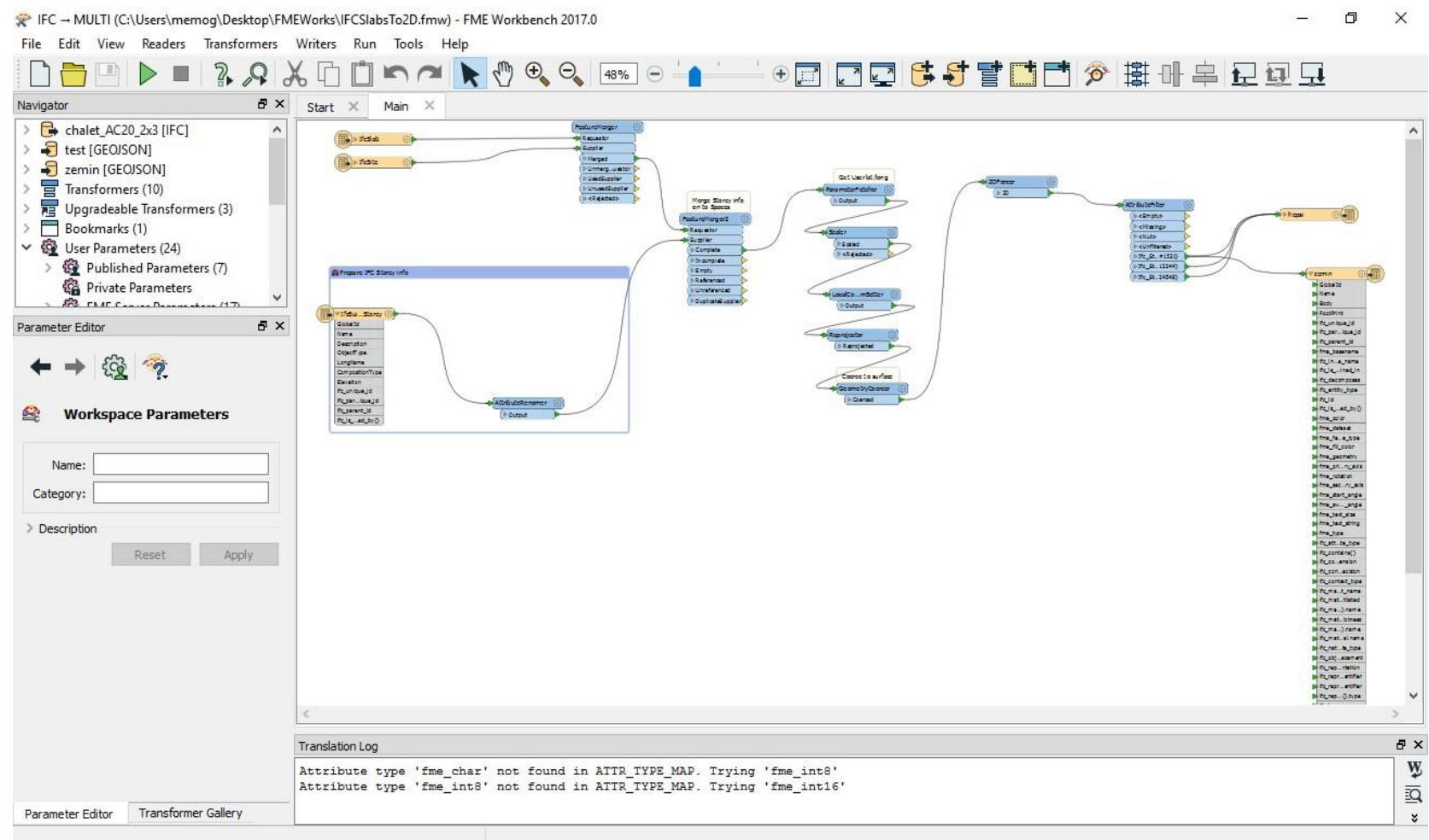

Figure 2. Transformation of Information Using FME

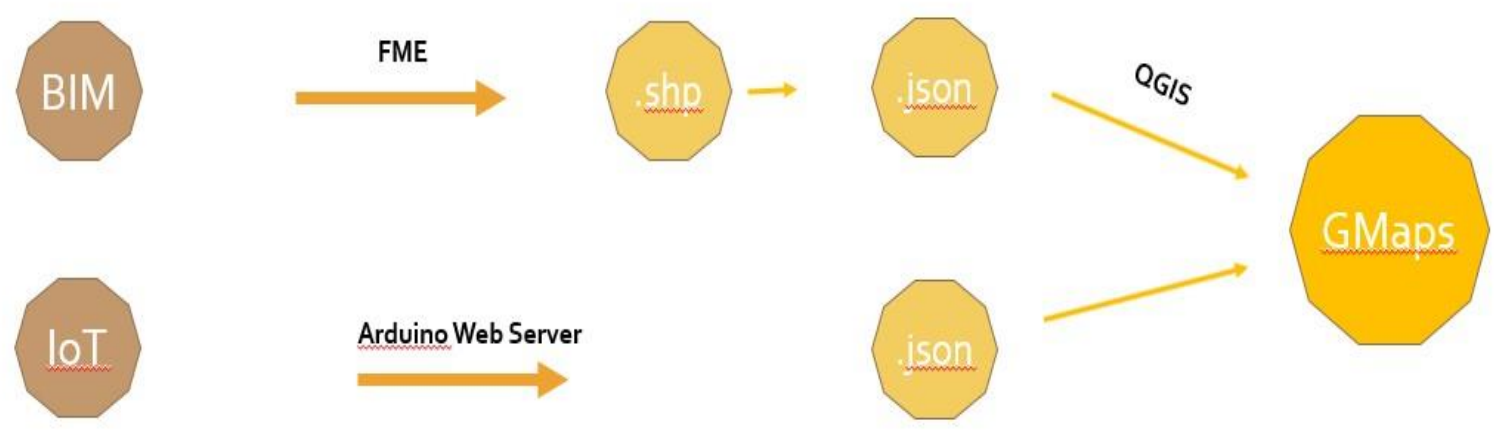

Figure 3. Integration Architecture 
ISPRS Annals of the Photogrammetry, Remote Sensing and Spatial Information Sciences, Volume IV-4/W4, 2017 4th International GeoAdvances Workshop, 14-15 October 2017, Safranbolu, Karabuk, Turkey

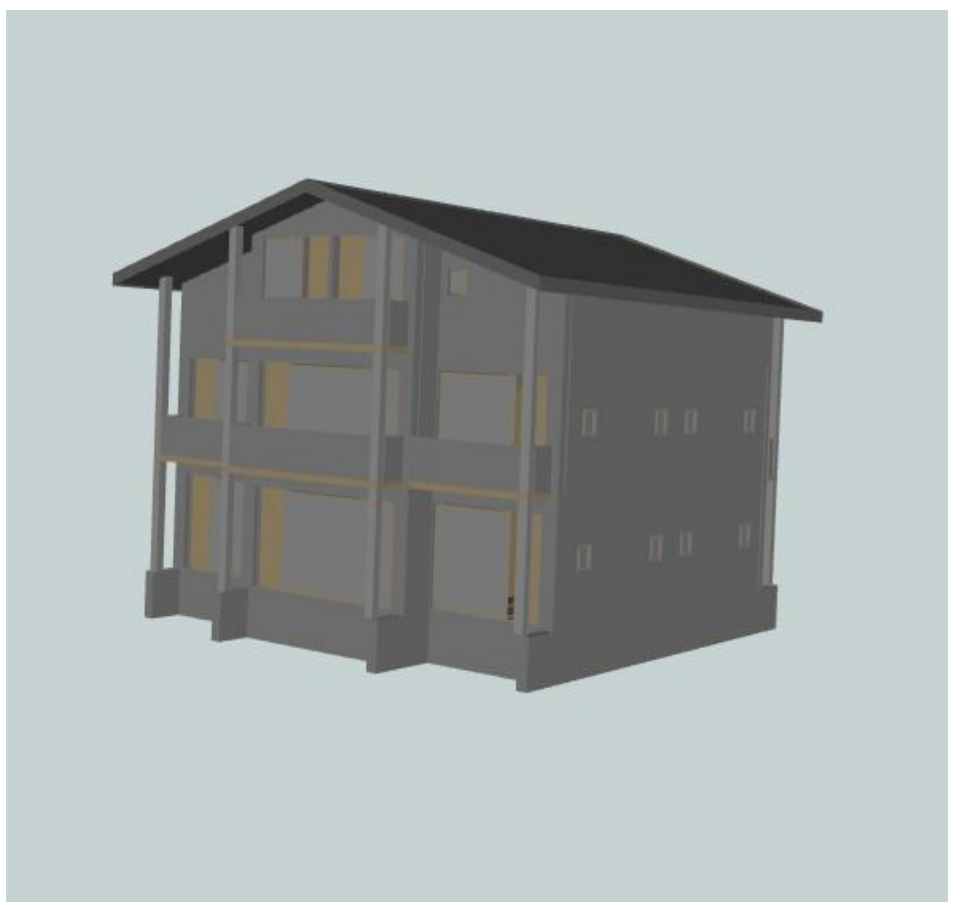

Figure 4.The visualization of BIM

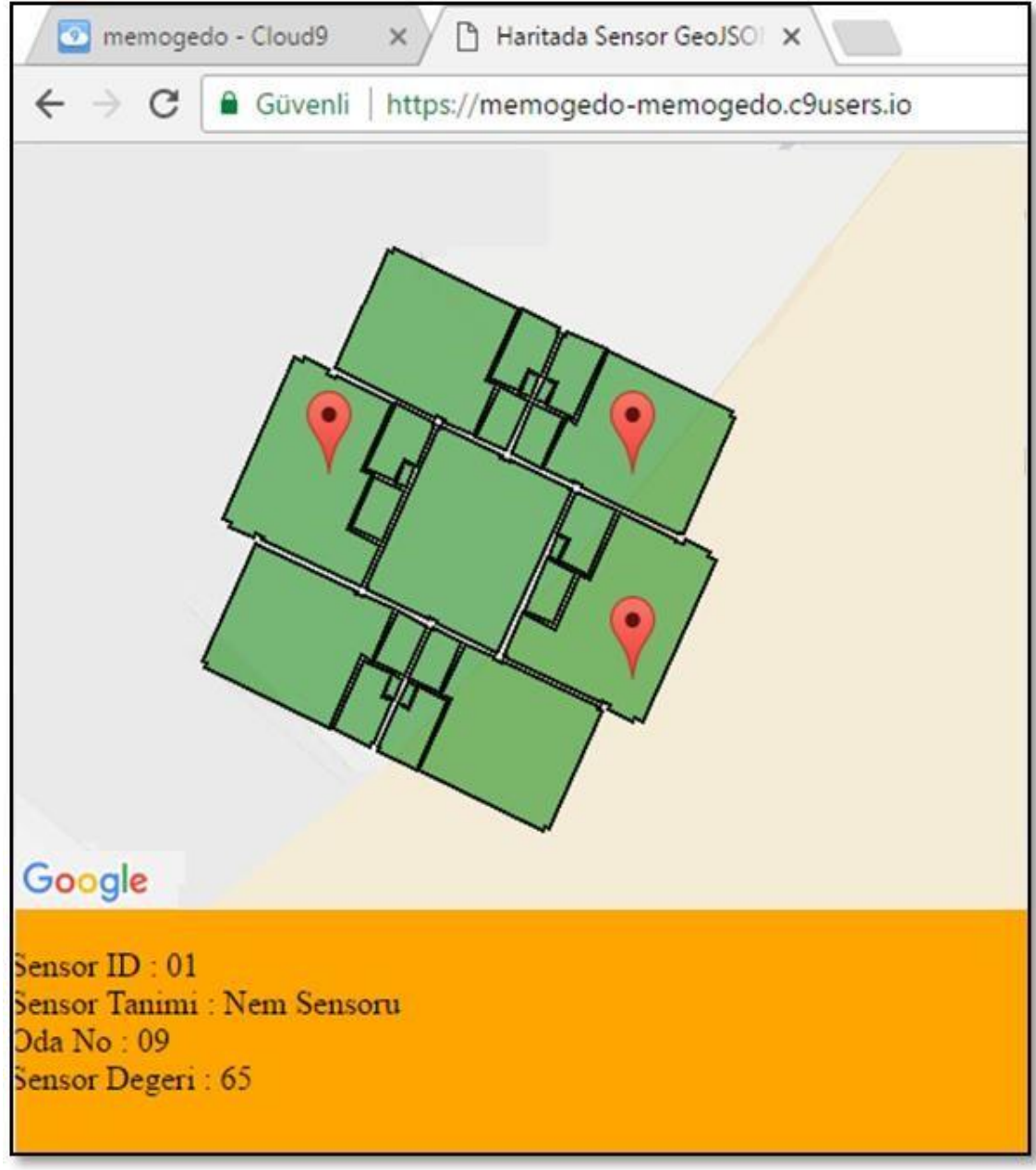

Figure 5. Visualization of Integrated Information 


\section{CONCLUSIONS}

Although the use of new technologies in FM seems to be a necessity, few studies have so far been done in a collaborative manner within this scope. Every field looked at a problem from its own perspective and tried to find a solution in itself. In this respect, the combined use of BIM, GIS and IoT technologies plays an important role for increasing the efficiency in facility management.

For this reason, our future efforts will continue in this direction and will focus on investigating the feasibility of this integration with different approaches in various contexts.

In this study, a facility in the BIM environment is displayed in two dimensions on Google Maps, and real-time data from the sensors can be provided and tracked from the web browser. Analysis and visualization of the data from the sensors will be important for facility managers, particularly in view of facility comfort analysis.

\section{REFERENCES}

Arduino - Introduction Arduino Getting Started | Foundation, Retrieved from https://www.arduino.cc/en/Guide/Introduction $\quad 05 \quad$ July 2017.

Atkin, B., Brooks, A., 2009. Total Facilities Management, 3rd ed, Wiley-Blackwell.

Bansal, V.K., Pal, M., 2009. Extended GIS for construction engineering by adding direct sunlight visualisations on buildings. Constr. Innov. Information, Process. Manag. 9 , 406-419. doi:10.1108/14714170910995949

Barker, I.C., 2013. A Practical Guide to Facilities Management. Whittles Publishing.

Barrett, P., Finch, E., 2014. Facilities Management - The Dynamics of Excellence, 3rd ed. Wiley Blackwell.

Begum, A., Saha, A.K., 2017. Sustainable Smart Cities in India, in: Sustainable Smart Cities in India. Springer

International Publishing, pp. 213-225. doi:10.1007/978-3-319-47145-7_14

Castro-Lacouture, D., Quan, S.J., Yang, P.P.J., 2014. GISBIM framework for integrating urban systems, waste stream and algal cultivation in residential construction. 31st Int. Symp. Autom. Robot. Constr. Mining, ISARC 2014 Proc. 576-583.

Deng, Y., Cheng, J.C.P., Anumba, C., 2016. A framework for 3D traffic noise mapping using data from BIM and GIS integration. Struct. Infrastruct. Eng. 2479, 1-14. doi:10.1080/15732479.2015.1110603

Deng, Y., Cheng, J.C.P., Anumba, C., 2016. Mapping between BIM and 3D GIS in different levels of detail using schema mediation and instance comparison. Autom. Constr. 67, 1-21. doi:10.1016/j.autcon.2016.03.006
El-gamily, H.I., Al-rasheed, K., 2015. Deploying an Interactive GIS System for Facility and Asset Management : Case Study-Ministry of Education , Kuwait. J. Geogr. Inf. Syst. 191-201. doi:10.4236/jgis.2015.72016

Ibrahim, K., 2016. BIM for FM : Input versus Output data BIM for FM : Input versus Output data. Proc. 33rd CIB W78 Conf. 2016, Oct. 31st - Nov. 2nd.

IFMA. Technology for Facility Managers : The Impact of Cutting-Edge Technology on Facility Management, edited by Eric Teicholz, John Wiley \& Sons, Incorporated, 2012. ProQuest Ebook Central,http://ebookcentral.proquest.com/ lib/yildiz/detail.actio n?docID=918225.

Isikdag, U., 2015. Enhanced Building Information Models Using IoT Services and Integration Patterns. SpringerBriefs in Computer Science. doi:DOI 10.1007/978-3-319-21825-

Kang, T., Park, S., Hong, C., 2016. BIM / GIS-based Data Integration Framework for Facility Management. GEOProcessing 2016 Eighth Int. Conf. Adv. Geogr. Inf. Syst. Appl. Serv. 100-105.

Kang, T.W., Hong, C.H., 2015. A study on software architecture for effective BIM/GIS-based facility management data integration. Autom. Constr. 54, 25- 38. doi:10.1016/j.autcon.2015.03.019

Kassem, M., Kelly, G., Dawood, N., Serginson, M., Lockley, S., 2016. Built Environment Project and Asset Management Article information:, in: Built Environment Project and Asset Management. Emerald Insight, pp. 261277

Laat, R. de, Berlo, L. van, 2011. Integration of BIM and GIS: The Development of the CityGML GeoBIM Extension. Adv. 3D Geo-Information Sci. Lect. Notes Geoinf. Cartogr. 211-225. doi:10.1007/978-3-64212670-3

Lee, W.-L., Tsai, M.-H., Yang, C.-H., Juang, J.-R., Su, J.Y., 2016. V3DM+: BIM interactive collaboration system for facility management. Vis. Eng. 4, 5. doi:10.1186/s40327-016-0035-9

Liu, S.J., Zhu, G.Q., 2014. The application of GIS and IoT technology on building fire evacuation. Procedia Eng. 71, 577-582. doi:10.1016/j.proeng.2014.04.082

Liu, X., Wang, X., Wright, G., Cheng, J., Li, X., Liu, R., 2017. A State-of-the-Art Review on the Integration of Building Information Modeling (BIM) and Geographic Information System (GIS). ISPRS Int. J. GeoInformation 6, 53. doi:10.3390/ijgi6020053

Niu, S., Pan, W., Zhao, Y., 2015. A BIM-GIS Integrated Web-based Visualization System for Low Energy Building Design. Procedia Eng. 121, 2184-2192. doi:10.1016/j.proeng.2015.09.091 
Petrenko, A., Sizo, A., Qian, W., Knowles, A.D., Tavassolian, A., Stanley, K., Bell, S., 2014. Exploring mobility indoors: An application of sensor-based and
GIS systems. Trans.
GIS
$18,351-369$.

doi:10.1111/tgis.12102

Roper, K.O., Borello, L.J., 2014. International Facility Management, 1st ed. Wiley Blackwell.

Strømann-Andersen, J., Sattrup, P.A., 2011. The urban canyon and building energy use: Urban density versus daylight and passive solar gains. Energy Build. 43, 2011-2020. doi:10.1016/j.enbuild.2011.04.007

Strzalka, A., Bogdahn, J., Coors, V., Eicker, U., 2011. 3D City modeling for urban scale heating energy demand forecasting. HVAC\&R Res. 17, 37-41. doi:10.1080/10789669.2011.582920

Wang, T., Krijnen, T., De Vries, B., Vries, B. de, 2016. Combining GIS and BIM for facility reuse: A profiling approach. Res. Urban. Ser. 4, 185-204.

doi:10.7480/rius.4.824

What is FME? FME Docs, 05 July 2017. Retrieved from https://docs.safe.com/fme/html/FME_Desktop_Docum entation/FME_Workbench/Workbench/What_is_FME .htm 